\title{
STUDY ON FAILURE PROCESS OF TAILING DAMS BASED ON PARTICLE FLOW THEORIES
}

\author{
Yuan, L.-W. ; Li, S.-M. ${ }^{* \#}$; Peng, B. ${ }^{* *} \&$ Chen, Y.-M.* \\ *Faculty of Land Resource Engineering, Kunming University of Science \& Technology, \\ Kunming, Yunnan, 650093, China \\ ** Hubei Changjiang Road \& Bridge Co., Ltd., Qichun, Huanggang, Hubei, China \\ E-Mail: kertylw@163.com,153064487@qq.com ${ }^{\#}$,420858827@qq.com,ch_yuming@163.com \\ $\left({ }^{\#}\right.$ Corresponding author)
}

\begin{abstract}
Based on a tailing dam project, tailing sands are simulated as discrete materials in this paper. Taking the distribution rule of tailing sands into account, the discrete element software PFC2D is adopted to examine the stability and instability process of the dam according to fundamental particle flow principles. The PFC2D model is established according to the deposition rule of tailing sands in the tailing dam then the function of strength reduction is proposed based on the principle of strength reduction to simulate the flooding condition as well as the factor of safety at the stable state and the displacement at the instability process under the particular condition. In addition, comparison is made with the limit equilibrium method and the obtained difference in factor of safety is discussed. The obtained factor of safety for the stability of dam slope from PFC2D analysis is higher than expectation mainly because the micro-parameters in PFC2D affect many macro-parameters simultaneously and the relation between micro-parameters and macro-parameters are nonlinear, which well fits engineering practice.
\end{abstract}

(Received in February 2015, accepted in May 2015. This paper was with the authors 2 months for 1 revision.)

Key Words: Tailing Dam, Particle Flow, PFC2D, Stability Analysis, Discrete Element, Numerical Simulation

\section{INTRODUCTION}

Once tailing dam failure occurs, it will have immeasurable impact on people's lives and properties as well as natural environment. Many accidents of tailing dam failure in statistics have claimed quantity of lives, properties and caused environmental damage [1]. The upstream filling method is mainly adopted for most area of China, which presents drawbacks in terms of complex dam structure, embedded layer with fine particles, low permeability and higher position of infiltration line. The stability therefore is unsatisfactory and study on stability of tailing dam is of significant practice for safe production [2, 3].

Two main methods are currently adopted in the stability analysis of tailing dam, namely limit equilibrium method and numerical simulation [4]. Once the limit equilibrium method is used for this aim, the location of slip surface is often assumed primarily and the rock-soil body is studied as rigid body, which presents great limitation on tailing sand materials. While the numerical methods such as finite element and finite discrete are used for this aim, although problems in the limit equilibrium method is overcome, tailing sands assumed as continuous elasto-plastic body deserves discussion in that tailing sands are non-uniform media for which the non-uniformity affects its stability. Analysis by particle-flow method of discrete element can well represent the non-uniform property of tailing dam and tailing sands which agrees well with practice [5].

Particle-flow discrete element is one branch of discrete elements which simulates the research object by assembly of spheres or circular particles rather than assembly of blocks. It can well simulate large-deformation problems as separation can be realized between particles. Currently software as PFC2D and PFC3D based on theory of particle-flow discrete element 
are extensively applied in domestic and oversea geotechnical projects. In 2000, Zhou et al. [6] carried out extensive geotechnical investigations by PFC software, and developed the particleflow code and conducted numerical simulations on the dual-axial experiments of sand samples. By comparison with results from laboratory tests, the particle-flow method was believed capable to simulate laboratory tests. Further studies by Zhou et al. [7] were conducted in 2002 where the indoor plain stain tests were simulated by PFC2D on clays and sands. Parameter study was carried out on the relation between micro-mechanical parameters and macro-mechanical responses. Some rules were revealed, which provides reference on the application of particle-flow theories in geotechnical engineering. In 2006, successful simulation was made by Zhou et al. [8] on permeability in soils using PFC2D where variation rules of pressure velocity during permeability were obtained and the results agree well with the Darcy's law. In 2009, the combined particle-flow theory, strength reduction and gravity increase was adopted by Zhou et al. [9] for study on factor of safety of slopes. The unique view in strength reduction method provides ideas for further studies. Other scholars carried out extensive researches on particle-flow simulations as well: Wang Y. et al. [10] simulated the deformation even failure process of sliding by the particle-flow discrete element based on site investigations. Through monitoring on the displacement, changes in porosity and displacement of different key locations, the rule of sliding failure along with time was interpreted. Wang et al. [11] conducted rock investigations on slopes by point-load apparatus and ShapeMetriX3D rock digital measurement. The accurate parameters of rock mass were modified by Hoek-Brown model, followed by micro-parameters from simulations on dualaxial tests and finally the real project of open slopes contributed to the building of particleflow model, by which the whole process of deformation, instability even failure of rock mass in hanging wall mining were examined.

\section{PARTICLE FLOW THEORIES}

The discrete element is proposed by Cundall in 1970's. The particle-flow discrete element is one of discrete elements which adopted the method in discrete elements to examine the movement and interaction [12] of circular particles. The PFC software developed from particle-flow discrete element was initially used as a tool to examine the property of particle materials as well as digital experiment of typical materials [13].

\subsection{Analysis on fundamental theories of particle flow}

Calculation principles of the particle-flow are mainly kinetic law (Newton's second law) and force-displacement law, for which the iteration process involves repetitive application of the kinetic law on each particle, repetitive application of the force-displacement law on each contact and continuous update of the wall position. Contact may occur between two spheres or between spheres and wall which automatically develops or damages in the simulation. At initial stage of each time-step, the contact is updated according to the known positions of particles and wall. Afterwards the force-displacement law enables the application of relative movement between two solid bodies to individual contact for update of the contact force. Following that based on the resultant force of contact force acting on particles and self-weight, the kinetic law is applied on individual particle to update its velocity and position. In addition, the wall position is updated as well according to the velocity through specified wall. After several iterations, the specified equilibrium state [14] is reached in the model.

(a) Laws of force-displacement

The law of force-displacement presents the relation of contacting force between two solid bodies and their displacement. The solid bodies here denote spheres and walls; the contact in 
particle-flow consists of 'sphere-sphere' contact (Fig. 1) and 'sphere-wall' contact (Fig. 2) [14].

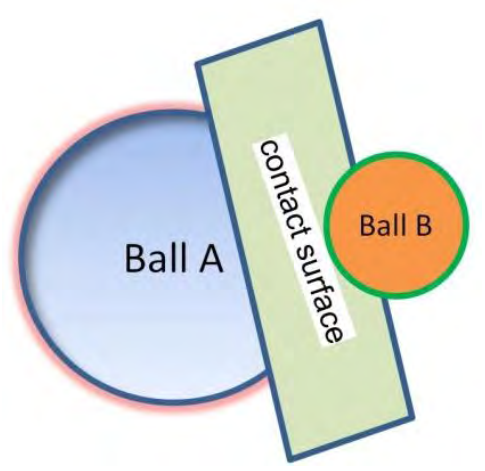

Figure 1: Sphere-sphere contact figure sketch.

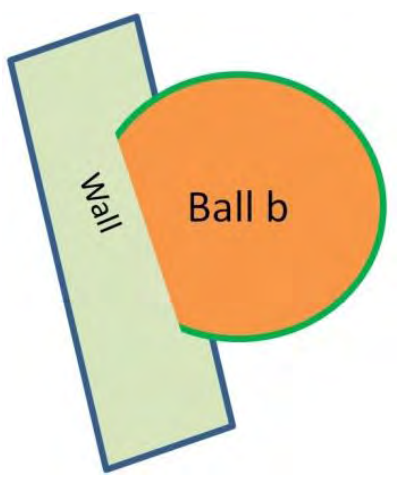

Figure 2: Sphere-wall contact figure sketch.

A, B and b are separate sphere names in Figs. 1 and 2. $\mathrm{W}$ is the wall name (no wall exists between $\mathrm{A}$ and $\mathrm{B}$ and the contact plain is the tangent plain of the two spheres). $R^{[\mathrm{A}]}, R^{[\mathrm{B}]}, R^{[\mathrm{b}]}$ are separate radius of spheres and $x_{i}^{[\mathrm{A}]}, x_{i}{ }^{[\mathrm{B}]}, x_{i}^{[\mathrm{b}]}$ are separate centre of spheres. $x_{i}^{[\mathrm{C}]}$ denotes the contact point of sphere-sphere or sphere-wall and $U^{n}$ the overlapping amount. For the sphere-sphere contact, $d$ represents the distance between the two centres of spheres while for the sphere-wall contact, $d$ is the shortest distance from the centre of sphere to the wall. $n_{i}$ denotes the unit normal vector of the plain given the two body contact.

For sphere-sphere contact, $n_{i}$ and $d$ can be calculated as:

$$
\begin{gathered}
n_{i}=\frac{x_{i}^{\mathrm{B}}-x_{i}^{\mathrm{A}}}{d} \\
d=\left|x_{i}^{\mathrm{B}}-x_{i}^{\mathrm{A}}\right|=\sqrt{\left(x_{i}^{[\mathrm{B}]}-x_{i}^{[\mathrm{A}]}\right)\left(x_{i}^{[\mathrm{B}]}-x_{i}^{[\mathrm{A}]}\right)}
\end{gathered}
$$

For sphere-wall contact, $n_{i}$ is associated with the zone where the sphere is located. In Fig. 3 , the active zone is divided into five parts where $\mathrm{AB}$ and $\mathrm{BC}$ are walls and black points are the centres of spheres. Once the sphere centre is located in different zones, $n_{i}$ is determined as presented in the figure: when the centre is located in Zone 2 and 4, $d$ is the shortest distance from the centre to the wall thus $n_{i}$ is perpendicular to the wall; when the centre is located in Zone 1, 3 and 5, $d$ is the distance from the centre to the zone corner thus $n_{i}$ is along the link from the centre to the corner.

The overlapping amount $U^{n}$ denotes the relative contact displacement along the normal direction, which can be determined by Eq. (3):

$$
U^{n}= \begin{cases}R^{[\mathrm{A}]}+R^{[\mathrm{B}]}-d & (\text { ball }- \text { ball }) \\ R^{\mathrm{b}}-d & (\text { ball }- \text { wall })\end{cases}
$$




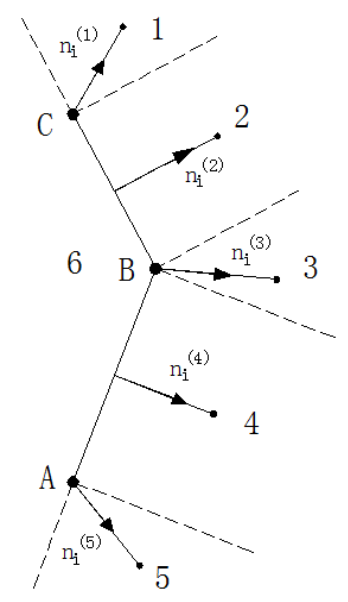

Figure 3: Determination of normal direction of contacting plain given sphere-wall contact.

The position of contact point is determined from Eq. (4) as follows:

$$
x_{i}^{[\mathrm{C}]}= \begin{cases}x_{i}^{[\mathrm{A}]}+\left(R^{[\mathrm{A}]}-\frac{1}{2} U^{n}\right) n_{i} & (\text { ball }- \text { ball }) \\ x_{i}^{[\mathrm{b}]}+\left(R^{[\mathrm{b}]}-\frac{1}{2} U^{n}\right) n_{i} & (\text { ball }- \text { wall })\end{cases}
$$

The contacting force vector $F_{i}$ given sphere-sphere contact and sphere-wall contact can be divided into the normal vector $F_{i}^{n}$ and tangent vector $F_{i}^{s}$ :

$$
\begin{gathered}
F_{i}=F_{i}^{n}+F_{i}^{S} \\
F^{n}=K^{n} U^{n}
\end{gathered}
$$

where $K^{n}$ is the normal stiffness of sphere which denotes the relation between total displacement and force.

The tangent contacting force is calculated in the form of increment. Once the contact develops, the initial total tangent contacting force is 0 , then the increase in shear displacement leads to the continuous increase of elastic tangent contacting force. The tangent contacting force is therefore calculated in the form of increment. After each iteration, the tangent contacting force is sum of former tangent force increments.

$$
\nabla F^{s}=-k^{s} \nabla U^{s}
$$

(b) Kinetic law

Movement of single rigid particle is determined by its resultant force and the resultant force vector acting on it, which can be described by the translation movement of a point in the particle as well as the rotation of this point. The translation is defined by the position $x_{i}$, velocity $\dot{x}_{i}$ and acceleration $\ddot{x}_{i}$; the rotation of particle is defined by angular velocity $\omega_{i}$ and angular acceleration $\dot{\omega}_{i}$.

Kinetic equation can be defined by two vector equations: one is about the resultant force and translation and the other the resultant moment and rotation.

The translation equation is:

$$
F_{i}=m\left(\ddot{x}_{i}-g_{i}\right)
$$

where $F_{i}$ is the resultant force of overall forces acting on the external surface of particle, $m$ the weight of particle and $g_{i}$ gravity acceleration.

The rotation movement equation is:

$$
M_{i}=\dot{H}_{i}
$$

where $M_{i}$ is the resultant moment acting on particle and $\dot{H}_{i}$ angular momentum. 
For two dimensional particle-flow, rotation only occurs along one plain thus the rotation equation can be simplified by the following Euler's equation:

$$
M_{3}=I \dot{\omega}_{3}=\left(\beta m R^{2}\right) \dot{\omega}_{3}
$$

where $\beta$ is $2 / 5$ for sphere particle and $1 / 2$ for circular disk particle.

Given the time $t$, the acceleration and angular velocity at the time increment $\Delta t$ are calculated as

$$
\begin{aligned}
& \ddot{x}_{i}^{(t)}=\frac{1}{\Delta t}\left(\dot{x}_{i}^{\left(t+\frac{\Delta t}{2}\right)}-\dot{x}_{i}^{\left(t-\frac{\Delta t}{2}\right)}\right) \\
& \dot{\omega}_{3}^{(t)}=\frac{1}{\Delta t}\left(\omega_{3}^{\left(t+\frac{\Delta t}{2}\right)}-\omega_{3}^{\left(t-\frac{\Delta t}{2}\right)}\right)
\end{aligned}
$$

From it:

$$
\begin{gathered}
\dot{x}_{i}^{\left(t+\frac{\Delta t}{2}\right)}=\dot{x}_{i}^{\left(t-\frac{\Delta t}{2}\right)}+\left(\frac{F_{i}^{(t)}}{m}+g_{i}\right) \Delta t \\
\omega_{3}^{\left(t+\frac{\Delta t}{2}\right)}=\omega_{3}^{\left(t-\frac{\Delta t}{2}\right)}+\left(\frac{M_{3}^{(t)}}{I}\right) \Delta t
\end{gathered}
$$

Finally the below equation is used to update the centre of particles and justify the contact state of particles:

$$
x_{i}^{(t+\Delta t)}=x_{i}^{(t)}+\dot{x}_{i}^{\left(t+\frac{\Delta t}{2}\right)} \Delta t
$$

Iteration in the kinetic law is carried out by the following approach. For the fixed $\dot{x}_{i}^{\left(t-\frac{\Delta t}{2}\right)}$, $\omega_{3}^{\left(t-\frac{\Delta t}{2}\right)}, x_{i}^{(t)}, F_{i}^{(t)}$ and $M_{3}^{(t)}, \dot{x}_{i}^{\left(t+\frac{\Delta t}{2}\right)}$ and $\omega_{3}^{\left(t+\frac{\Delta t}{2}\right)}$ can be obtained. $x_{i}^{(t+\Delta t)}$ can be obtained using above equations. Finally $F_{i}^{(t+\Delta t)}$ and $M_{3}^{(t+\Delta t)}$ can be obtained based on the rule of forcedisplacement, which is applied in the next iteration.

\subsection{Constitutive models of interface}

Constitutive property of materials in PFC2D is presented by different contact constitutive models. Contact constitutive models of particles mainly involve three types: a) contact stiffness model which presents the elastic relation of contacting force and the relative displacement; b) sliding model which presents the relation between tangent contacting force and normal contacting force. Sliding is possible between the tact of two spheres; c) bond model which governs the total normal force and tangent force by attribution of certain bond strength at the contact.

\subsection{Analysis on failure judgement of rocks/soils by PFC}

A failure criterion shall be defined in stability analysis by numerical modelling on soil-rock mass, e.g., a scenario that indicates the soil-rock mass fails. When numerical methods, such as the finite element method and finite discrete method, are adopted in stability analysis of soilrock mass [9], three conventional failure criterions are a) criterion of interconnection of plastic zones; b) non-convergence of calculation; c) criterion of displacement mutation.

PFC2D is a discrete software based on force-displacement analysis in which particles can directly break away from the model thus it is reasonable to conduct comparison of actual displacement and limit displacement to justify the failure of soil-rock mass. In practical calculation of factor of safety, iteration is required thus the termination of calculation cannot only base on limit displacement. The default of calculation in PFC2D can reach the equilibrium criterion, when the ratio of maximum unbalanced force over the maximum 
contacting force is lower than 0.01 and meantime the ratio of average unbalanced force over the average unbalanced contacting force is lower than 0.01 . This ratio can be taken as $1 \mathrm{e}-5$ for more accuracy, i.e., calculation terminates when both the two ratios can be met and no obvious displacement occurs on particles.

\section{CASE ANALYSIS OF FAILURE SIMULATION}

\subsection{Background of the tailing dam}

The tailing dam is located at erosion valley gully. The peak elevation in this region is around $900 \mathrm{~m}$ and lowest elevation $245 \mathrm{~m}$ with relative difference $655 \mathrm{~m}$. The gully is ' $\mathrm{V}$ ' type with steep bank. The slope at right bank is $40^{\circ} \sim 50^{\circ}$ and left bank $45^{\circ} \sim 55^{\circ}$ with considerable cut depth (general cut depth $30 \sim 50 \mathrm{~m}$ with width $10 \sim 20 \mathrm{~m}$ ).

The initial dam is $20 \mathrm{~m}$ in height and $49.46 \mathrm{~m}^{3}$ in volume. Mainly the upstream filling method is adopted on the filing dam with dam height $85.2 \mathrm{~m}$ and dam volume $14.28 \times 10^{6} \mathrm{~m}^{3}$. According to site investigation records of the tailing dam, the tailing dam mainly comprises tailing fine sands, tailing silty sands and tailing silts. Each property is presented in Table I and permeability coefficient in Table II.

Table I: The physical mechanical parameters of tailing dam.

\begin{tabular}{|l|c|c|c|c|c|c|}
\hline Materials & $\begin{array}{c}\text { Unit weight } \\
\left(\mathrm{kN} / \mathrm{m}^{3}\right)\end{array}$ & $\begin{array}{c}\text { Saturated } \\
\text { unit weight } \\
\left(\mathrm{kN} / \mathrm{m}^{3}\right)\end{array}$ & $\begin{array}{c}\text { Elastic } \\
\text { modulus } \\
(\mathrm{MPa})\end{array}$ & $\begin{array}{c}\text { Possion's } \\
\text { ratio }\end{array}$ & $\begin{array}{c}\text { Cohesion } \\
(\mathrm{kPa})\end{array}$ & $\begin{array}{c}\text { Friction } \\
\text { angle (deg. })\end{array}$ \\
\hline Initial dam & 22 & 22 & 70 & 0.22 & 0 & 33 \\
\hline Fine sand & 18.5 & 19 & 38 & 0.30 & 4.0 & 21.8 \\
\hline Silt & 19 & 19.5 & 35 & 0.30 & 4.4 & 20.4 \\
\hline Floury soil & 20.5 & 21 & 30 & 0.35 & 6.0 & 18 \\
\hline Bedrock & 23 & 23 & 200 & 0.28 & 120 & 27 \\
\hline
\end{tabular}

Table II: The permeability coefficient parameters of tailing dam.

\begin{tabular}{|l|c|c|}
\hline Materials & $\begin{array}{c}\text { Horizontal permeability } \\
\text { coefficient }(\mathrm{cm} / \mathrm{s})\end{array}$ & $\begin{array}{c}\text { Vertical permeability } \\
\text { coefficient }(\mathrm{cm} / \mathrm{s})\end{array}$ \\
\hline Initial dam & $3 \times 10^{-3}$ & $3 \times 10^{-3}$ \\
\hline Fine sand & $1.3 \times 10^{-3}$ & $7.5 \times 10^{-4}$ \\
\hline Silt & $6.8 \times 10^{-4}$ & $3.4 \times 10^{-4}$ \\
\hline Floury soil & $2.4 \times 10^{-4}$ & $1.2 \times 10^{-4}$ \\
\hline Bedrock & 0 & 0 \\
\hline
\end{tabular}

\subsection{Development of PFC2D model of tailing dam}

In PFC2D modelling, consistency [15] shall be made between the modelling environment and the triaxial test environment (for calibration of micro-parameters) to ensure the function of selected micro-parameters, i.e., wall stiffness, friction coefficient, sphere radius and initial stress shall be consistent with them in triaxial tests. Modelling process in PFC2D is in general consistent with that in sample modelling of triaxial tests with minor difference.

Firstly tailing sands are classified into tailing fine sands, tailing silty sands and tailing silts and each layer of tailing sands presents distinctions. Different materials shall be modelled by blocks and the schematic model is presented in Fig. 4.

Moreover the distribution of particle sizes in tailing dam is considered in the modelling and the distribution rule can be illustrated after curve-fitting by Eq. (16), which requires separately models on regions with different particle sizes. 


$$
D=\frac{0.175}{L^{0.157}} \times 10^{-3}
$$

where $L$ is the horizontal distance from one point to the drawhole $m$, and $D$ denotes the average particle size of tailing sands, in $\mathrm{mm}$.

(a) Wall modelling

Wall element in PFC2D has two functions: a) to fix and maintain the model shape (no cohesion effect is activated between spheres for the initial model thus spheres will disperse without restriction); b) as the boundary condition. Walls in tailing dam models can be classified into two types according to the above functions: one is to maintain the shape of individual soil layer based on divided blocks and the other is to restrict the velocity and displacement of boundary spheres. The later walls will exist all along the post-calculation while the former shall be deleted in the calculation.

\section{(b) Sphere modelling}

The tailing dam model mainly consists of five materials including bedrock, filling dam, tailing fine sands and tailing silts. To start with, corresponding spheres to above five materials shall be generated separately. In addition, for tailing materials, rule shall be followed that the more distance from dam slope, the finer corresponding radius of sphere [16]. According to Eq. 16 , the average size of tailing sands in every $100 \mathrm{~m}$ dry beach is calculated then some ratio of enlarging is adopted on the size (too many particles once the generation follows the real particle size thus no result is obtained from computation) which serves at the size range in every $100 \mathrm{~m}$. Following the two principles, the tailing dam model is divided into blocks then corresponding spheres are generated. Finally 63107 spheres in total are generated in the model.

(c) Generation of initial stress field and elimination of floating particles

The loading condition of the internal model generated after the two steps above is inconsistent with that from the triaxial test. Load attribution is not uniform thus small initial stress shall be assigned till the uniform stress condition is acquired. After this stage floating particles with contact smaller than 3 still exist, e.g. the black particles presented in Fig. 4. These floating particles without treatment will influence the following model execution, e.g. great distinction exists between monitoring records on unbalanced force, displacement as well as velocity etc. and factual conditions. In general local enlarging or shrinking on particles is a practical approach to eliminate floating particles until contact of each sphere is no less than 3 .

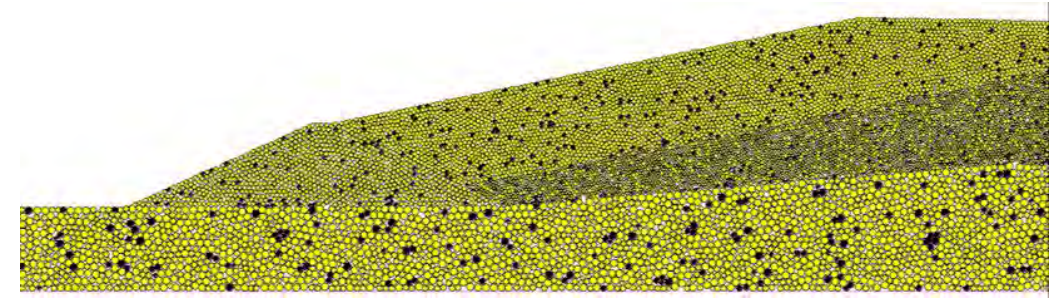

Figure 4: Floating particles in the tailing dam model.

\section{(d) Property allocation and modelling}

Material properties are assigned on individual soil layer in the model according to calibration on micro-parameters of these materials then the model is run till the equilibrium condition. After that, wall elements for model shaping are deleted and wall elements as boundary condition are left. After setting on gravity acceleration, the model reaches initial stress equilibrium. Following that, the velocity and displacement of spheres in the model are offset as 0 for conduction of stability analysis. The PFC2D model of the tailing dam is hereto completed. 


\subsection{Analysis on failure process of tailing dams simulated by particle flows subject to particular conditions (flood and earthquake)}

Water has a significant effect on stability of tailing dams. In numerical modelling the calculated infiltration line is imported into the particle-flow model. The balance diagrams of particle-flow model for the tailing dam under gravity effect are presented in Figs. 5 and 6, separately given the normal water level, flooding level and particular condition, where red particles occupy the above infiltration line part, green ones occupy the below infiltration line part and blue ones the bedrock part. Particles are labelled by white every other $10 \mathrm{~m}$ along both the vertical direction and horizontal direction of the model for easy observation of damage and deformation of the model.

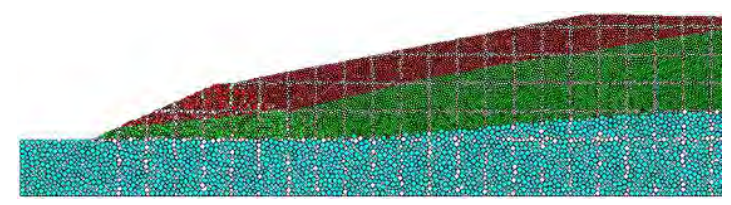

Figure 5: Diagram of balance condition for the tailing dam under flooding condition and gravity effect.

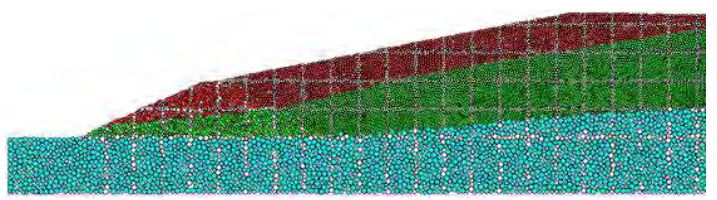

Figure 6: Diagram of balance condition for the tailing dam under special conditions.

Stability analysis is carried out here taking the case under particular condition as an example. In general earthquakes will induce liquefaction of tailing dams thus reduce their stability. The seismic fortification degree for the dam location is 7 degree thus the horizontal acceleration is taken as $0.10 \mathrm{~g}$ when the seismic effect is simplified by pseudo-static method. The factor of safety of dam under flooding condition after strength reduction is 1.844 .

The reduction coefficient of 1.844 is taken to conduct reduction on parameters of each layer of tailing dam model under particular condition and deformation diagrams at instability given that different time-step are presented in Figs. 7, 8, 9 and 10 as well as displacement vector diagrams presented in Figs. 11, 12, 13 and 14.

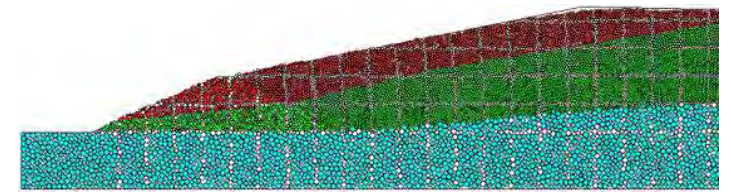

Figure 7: Buckling deformation figure (step $=25000)$.

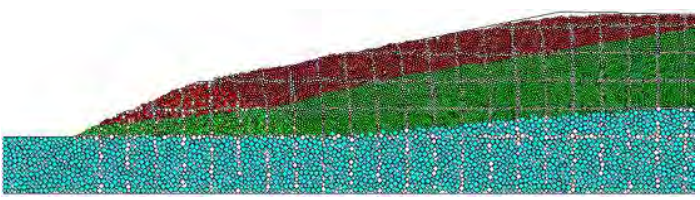

Figure 8: Buckling deformation figure (step $=50000)$.

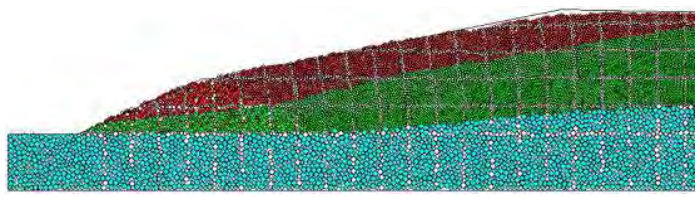

Figure 9: Buckling deformation figure ( 


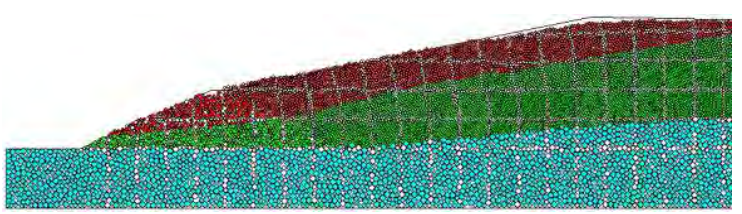

Figure 10: Buckling deformation figure (step $=100000)$.

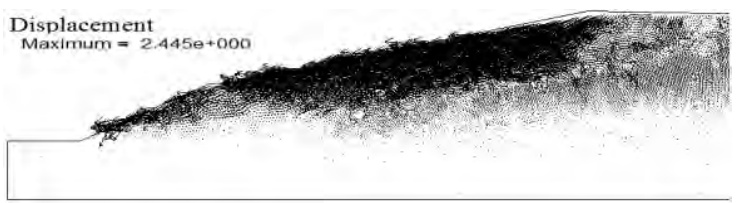

Figure 11: Displacement vector diagram about Dam slope $($ step $=25000)$.

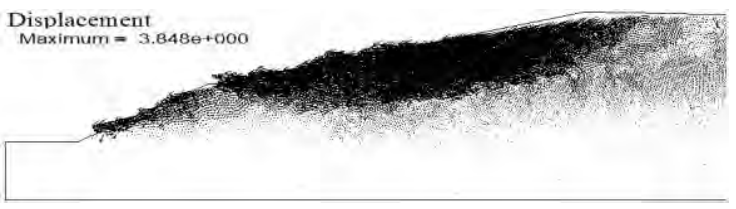

Figure 12: Displacement vector diagram about Dam slope (step=50000).

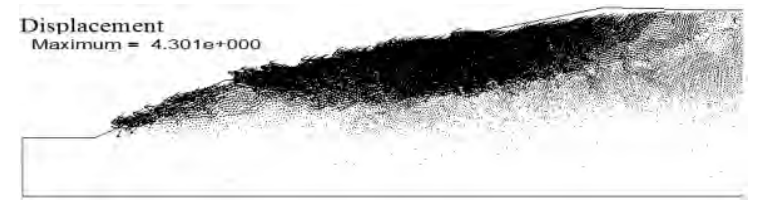

Figure 13: Displacement vector diagram about Dam slope (step =75000).

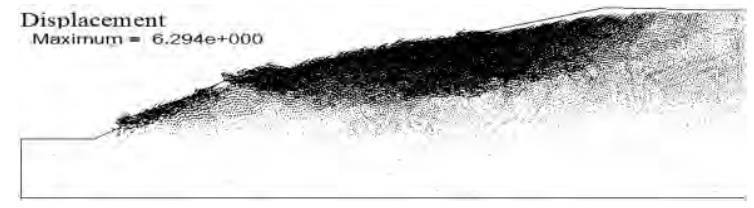

Figure 14: Displacement vector diagram about Dam slope $($ step = 100000).

Comparison is made in terms of deformation diagram at instability and displacement vector diagram between the particular condition and the flooding condition: the deformation diagram at instability under flooding condition is presented in Fig. 15 and the displacement vector diagram of dam is in Fig. 16.

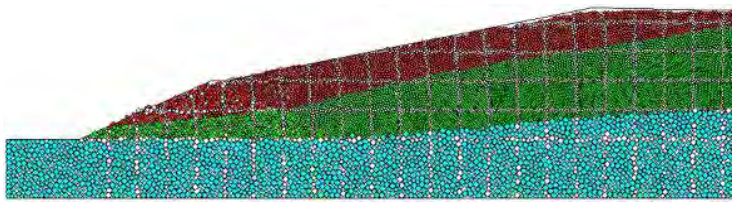

Figure 15: Displacement vector diagram about Dam slope under flooding condition and gravity effect $($ step $=100000)$.

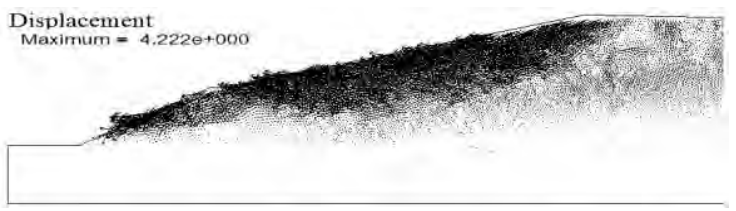

Figure 16: Displacement vector diagram about Dam slope under flooding condition and gravity effect $($ step $=100000)$. 
It is seen from Figs. 7, 8, 9 and 10 that the inclination of marked white strips is very obvious, which indicates the deformation and damage of both initial dam and filling dam is larger than that under flooding and the deformation at the slope toe is more obvious.

It is seen from Figs. 11, 12, 13 and 14 that the failure surface of filling dam is deeper than the flooding level and the total displacement is larger than that given the flooding condition.

\subsection{Results and Discussions}

The calculated factor of safety from PFC2D modelling on tailing dam under particular condition is 1.844 whereas it is 1.214 from calculation by Swedish circular method (calculation not presented here). Results from both methods indicate the stable condition of the tailing dam and the factor of safety obtained from PFC2D analysis is higher due to the following two main reasons:

(a) After examination on micro-parameters and macro-parameters, for contact cohesion materials, negative correlation is found between the friction coefficient of micro-parameters and the cohesion of macro-parameters, also between the cohesion strength of microparameters and the internal friction angle of macro-parameters. The strength reduction in PFC2D is the simultaneous reduction on both friction coefficient and cohesion strength while the negative correlation will reduce the reduction degree of corresponding cohesion and internal friction angle.

(b) Although no correspondence can be found between micro-parameters and macroparameters, micro-parameters are associated with higher reduction coefficient. For instance on cohesionless materials, the friction coefficient of 2.84 is associated with internal friction angle of $38.12^{\circ}$; the friction coefficient of 0.71 is associated with internal friction angle of $30.06^{\circ}$; i.e., the corresponding reduction coefficient is 4 for the friction coefficient and the corresponding reduction coefficient is 1.36 for the internal friction angle.

\section{CONCLUSIONS}

Calculation and analysis are made in this paper by PFC2D to obtain the factor of safety under individual construction condition of tailing dams. Results indicate the progress of dam failure together with its strength reduction, as follows: given the normal water table, the sliding process for the initial dam begins with the sliding at its lower position which leads to the following upper sliding. The two processes appear alternatively and the same scenario occurs on the filling dam; given the flooding or particular condition, failure pattern of the initial dam is overall sliding of the slope surface while for the filling dam, failure begins with the considerable sliding at the lower position, which then accelerates the sliding on the upper part.

The factor of safety obtained from PFC2D simulations is compared with that from Swedish circular method. Analysis is carried out to examine the main reasons for the obtained higher factor of safety from PFC2D modelling, as follows: a) negative relation is found between the friction coefficient and cohesion in reduced micro-parameters, which increases the cohesion in every reduction. Another negative relation is found between the cohesive strength and the internal friction angle, which increases the internal friction angle in every reduction; b) the reduction coefficient of friction coefficient in micro-parameters is bigger than the corresponding reduction coefficient of internal friction angle in macro-parameters.

\section{ACKNOWLEDGEMENTS}

This work was funded by the Natural Science Foundation of provincial people training project of Kunming University of Science \& Technology (No: KKSY201421072) and the State Administration 
of Work Safety Production major accident prevention technology projects focus on key technologies (No: 10-101). Corresponding author: Li, Sumin.

\section{REFERENCES}

[1] Yuan, L.-W.; Jin, L.-Z; Chen, Y.-M. (2013). Research of tailings pond supervision level classification system based on disaster risk, Metal Mine, Vol. 445, No. 7, 153-158, doi:10.3969/j.issn.1001-1250.2013.07.039

[2] Zhang, L.-Z. (2013). Summary on the dam-break of tailing pond, Journal of Hydraulic Engineering, Vol. 44, No. 5, 594-600

[3] Yu, G.-M.; Song, C.-W., Pan, Y.-Z.; Li, L.; Li, R.; Lu, S.-B. (2014). Review of new progress in tailing dam safety in foreign research and current state with development trend in China, Chinese Journal of Rock Mechanics and Engineering, Vol. 33, No. S1, 3238-3248

[4] Yu, S.-Z.; Shao, L.-T.; Liu, S.-Y. (2013). Stability analysis of tailings dam based on finite element limit equilibrium method, Rock and Soil Mechanics, Vol. 34, No. 4, 1185-1190

[5] Zhang, X.-X; Wang, B.-S.; Chi, Y.-P.; Lyu, Z.-Q. (2015). A particle flow method of slope stability analysis, Journal of Harbin Engineering University, Vol. 36, No. 5, 666-670

[6] Zhou, J.; Chi, Y.-W.; Chi, Y.; Xu, J.-P. (2000). Simulation of biaxial test on sand by particle flow code, Chinese Journal of Geotechnical Engineering, Vol. 22, No. 6, 701-704, doi:10.3321/ j.issn:1000-4548.2000.06.014

[7] Zhou, J.; Liao, X.-H.; Chi, Y.; Xu, J.-P. (2002). Simulating plane strain test of soils by particle flow code, Journal of Tongji University (Natural Science), Vol. 30, No. 9, 1044-1050, doi:10.3321/j.issn:0253-374X.2002.09.003

[8] Zhou, J.; Zhang, G.; Kong, G. (2006). Meso-mechanics simulation of seepage with particle flow code, Journal of Hydraulic Engineering, Vol. 37, No. 1, 28-32, doi:10.3321/j.issn:05599350.2006.01.005

[9] Zhou, J.; Wang, J.-Q.; Zeng, Y.; Jia, M.-C. (2009). Slope safety factor by methods of particle flow code strength reduction and gravity increase, Rock and Soil Mechanics, Vol. 30, No. 6, 1549-1554, doi:10.3969/j.issn.1000-7598.2009.06.003

[10] Wang, Y.; Li, X.; Wang, S.-X.; Hou, W.-S. (2012). PFC simulation of progressive failure process of landslide, Journal of Yangtze River Scientific Research Institute, Vol. 29, No. 12, 46-52, doi:10.3969/j.issn.1001-5485.2012.12.010

[11] Wang, P.-T.; Yang, T.-H.; Yu, Q.-L.; Liu, H.-L.; Zhang, P.-H. (2013). On obtaining jointed rock slope geo-parameters and the application of PFC2D, Journal of Mining \& Safety Engineering, Vol. 30, No. 4, 560-565

[12] Pan, B.-C.; Shi, Q.-F.; Sun, G. (2014). Inner structure of granular pile during its quasi-static avalanches and slow flows, Acta Physica Sinica, Vol. 63, No. 1, 6 p., doi:10.7498/aps.63.014703

[13] Song, Y.-L.; Xia, C.-C.; Tang, Z.-C.; Song, Y.-G. (2013). Numerical simulation and test validation for direct shear properties of rough joints under different contact states, Chinese Journal of Rock Mechanics and Engineering, Vol. 32, No. 10, 2028-2035

[14] Sun, Q.-C.; Wang, G.-Q. (2008). Review on granular flow dynamics and its discrete element method, Advances in Mechanics, Vol. 38, No. 1, 87-100, doi:10.3321/j.issn:1000-0992.2008. $\underline{01.006}$

[15] Zhang, Z.-H.; Zhang, G.-D.; Li, M.-D.; Liao, W.; Xu, Z.-H. (2014). The influence of mesoscopic parameters in particle flow model on macro-reaction of coarse grained soil, Journal of Hydraulic Engineering, Vol. 45, No. S2, 215-220

[16] Liu, G.; Rong, G.; Peng, J.; Hou, D.; Zhou, C.-B. (2013). Mechanical behaviors of rock affected by mineral particle shapes, Chinese Journal of Geotechnical Engineering, Vol. 35, No. 3, 540550 